\title{
Da inclusão à evasão escolar: o papel da motivação no ensino médio
}

\author{
From inclusion to dropout: The role of \\ motivation in high school students
}

Marcelo Simões MENDES

\begin{abstract}
Resumo
Neste artigo procurou-se refletir a respeito dos processos de inclusão e evasão escolar no Ensino Médio sob o enfoque de como a motivação pode se associar aos mesmos. Para este fim, foi realizada uma análise sobre as implicações que tais processos acarretam na vida dos estudantes, procurando-se perceber como a variável motivacional pode apresentar-se tanto como consequência do processo de inclusão como estar relacionada às causas da evasão por parte do aluno. Fica evidente a importância que o papel da motivação adquire no contexto escolar, o que vem a fomentar um campo de discussões cada vez mais abrangente e significativo na área de Psicologia da Educação.
\end{abstract}

Unitermos: Evasão; Inclusão; Motivação.

\begin{abstract}
The aim of this article is to reflect on the processes of inclusion and dropout among High School students from the standpoint of how motivation can bring them together. For this, an analysis of the implications that these processes entail in the lives of students was carried out, seeking to comprehend how the motivation variable can appear as a result of the inclusion process or can be related to the causes of the dropout of the student. It is evident how important the role of motivation is in the school context, which encourages a more comprehensive and meaningful field of discussion from the area of Educational Psychology.
\end{abstract}

Uniterms: Dropout; School inclusion; Motivation.

No ambiente escolar, muito se tem discutido sobre os processos de inclusão do aluno, assim como sobre as questões relativas à sua permanência na escola. Ao se pensar no termo inclusão, não é difícil associá-lo a pessoas com necessidades especiais, como, por exemplo, deficientes auditivos, paraplégicos, entre outros. De fato, a origem das discussões sobre inclusão escolar teve como ponto de partida sujeitos com algum tipo de deficiência. Para Sant'Ana (2005), nas últimas décadas e especialmente após a Declaração de Salamanca, em 1994, a questão da inclusão escolar de crianças com necessidades especiais no ensino regular tem se tornado alvo de pesquisas e eventos científicos, abrangendo discussões que permeiam desde concepções teórico-filosóficas quanto aquelas associadas à implementação preconizadas por tal declaração. No entanto, os debates

$\boldsymbol{\nabla} \boldsymbol{\nabla} \boldsymbol{\nabla}$

1 Universidade Paulista. Av. Comendador Enzo Ferrari, 280, Swift, 13043-900, Campinas, SP, Brasil. E-mail: <m_smendes@yahoo.com.br>.

Agradecimento: à Coordenação de Aperfeiçoamento de Pessoal de Nível Superior. 
realizados atualmente já não se restringem somente aos alunos portadores de algum tipo de deficiência. Segundo Sanches e Teodoro (2006), a inclusão escolar "deve contemplar todas as crianças e jovens com necessidades educativas" (p.69).

Neste processo tão amplo, alguns autores advertem sobre como certas práticas podem, ao invés de incluir de forma efetiva o aluno em suas atividades acadêmicas, corroborar para excluí-lo ainda mais do seu universo estudantil. Mittler (2003) relata que, ao encaminhar os alunos que apresentam dificuldades de aprendizagem para turmas de suporte especializado, este ato, por si mesmo, já consiste em uma maneira de segregação, à medida que denota déficits no processo de ensino e aprendizagem. Este autor defende uma mudança no currículo escolar no sentido de integrar os propósitos que a escola pretende atingir a partir das necessidades que os estudantes apresentam.

Os projetos que visam à implantação de uma prática inclusiva no contexto escolar deixam de se tornar efetivos por várias razões. No estudo de Leonardo, Bray e Rossato (2009), foram investigados 26 professores da Educação Básica que possuem alunos com deficiência de escolas do interior do Paraná divididos em dois grupos (10 - Escolas Públicas; $2^{\circ}$ - Escolas Privadas). Nos dois grupos, os resultados demonstraram um despreparo tanto por parte dos professores para lidar com a diversidade em sala de aula quanto pela falta de infraestrutura oferecida pelas escolas.

Em outro tipo de discussão sobre a Educação Inclusiva, é possível tecer considerações sobre as implicações que o discurso da mesma revela sobre diversos níveis do processo ensino-aprendizagem. Nesta direção, Cavallari (2010) alerta para o fato de que a prática e política inclusivas denominam alguns conceitos dicotômicos, como, por exemplo, exclusão versus inclusão e diferença versus igualdade. Segundo a autora, estes conceitos extremamente simplificadores de um processo tão complexo incidem sobre a constituição identitária dos alunos, uma vez que estes recebem as denominações de incluídos e excluídos.

Nesta direção, partindo do pressuposto de que a Educação Inclusiva possui a generalização como um de seus princípios constituintes, uma escola que inclua deve ter, mesmo que implicitamente, propostas que consigam atender a todos os alunos, desde estudantes com dificuldades para chegar à sala de aula até aqueles que necessitem de apoio por superdotação. É sob esta concepção que a inclusão escolar apresenta um ponto crítico e delicado.

Propor a inclusão no sentido de homogeneizar a demanda dos excluídos, sem que estes recebam atendimento especializado para suas necessidades, pode, em contrapartida, gerar outros tipos de consequências. Como aponta Plaisance (2010), colocar em um mesmo espaço não significa que a exclusão foi erradicada. Um aluno pode estar matriculado em uma escola regular e, mesmo assim, sofrer rejeições e ser marginalizado devido às dificuldades que enfrenta. Em decorrência disso, outro fator pode ser afetado: a motivação, ou a falta dela.

De fato, o processo de inclusão pode acarretar efeitos diretos na motivação do aluno e, desta forma, estar associado à sua permanência ou evasão da escola. Para Bzuneck (2009), a motivação é aquilo que move uma pessoa, que a põe em ação ou a faz mudar de curso. A motivação tem sido entendida ora como um fator psicológico, ou conjunto de fatores, ora como um processo. Existe um consenso entre autores a respeito da dinâmica destes fatores, que levam a uma escolha, a uma investigação, fazem o sujeito iniciar um comportamento direcionado a um determinado objetivo (Bzuneck, 2009; Costa \& Boruchovitch, 2006).

Pensando no contexto do Ensino Médio, em uma pesquisa de âmbito nacional em que participaram mais de 50 mil alunos e 7 mil professores, foi constatado que o principal problema deste nível de ensino consiste no desinteresse dos alunos frente às atividades escolares. Neste estudo, sob a perspectiva do aluno, este problema foi apontado por 6 em cada 10 estudantes. Em relação aos professores, esta questão ficou ainda mais evidenciada, pois três quartos dos docentes entendem que o principal problema no Ensino Médio são os alunos desinteressados (Abramovay \& Castro, 2003).

No estudo desenvolvido por Machado (2005), participaram 30 alunos (17 do sexo masculino e 13 do feminino) do Ensino Médio de uma escola estadual de Campinas, estado de São Paulo, com idade de 16 a 19 anos, aproximadamente, e nível socioeconômico médio/baixo. O objetivo do estudo foi examinar as percepções dos participantes sobre as variadas dimensões do meio escolar, relacionando-as com o desenvolvimento pessoal e a motivação para aprender dos alunos. 
Como resultados, os autores obtiveram que menos da metade dos alunos se consideravam motivados a ir à escola e, dentre estes, a menor parte tinha prazer em estudar.

Algumas consequências decorrentes do déficit na motivação do aluno (seja ela considerada em termos qualitativos ou quantitativos) podem ter relação direta em seu processo de aprendizagem. Para Bzuneck (2009), a queda na motivação leva a um declínio no investimento pessoal para realizar as tarefas de aprendizagem com qualidade, o que impossibilita a formação de indivíduos mais competentes para exercerem a cidadania e se realizarem como pessoas. Como relatado anteriormente, tal fato pode contribuir para que o estudante se empenhe cada vez menos em suas atividades escolares e, com isso, acabe evadindo do contexto escolar. A fim de melhor compreender o fenômeno de evasão escolar, é preciso diferenciar seu conceito daquele entendido como abandono escolar. Evasão escolar refere-se ao aluno que deixa a escola, mas com a possibilidade de retorno à mesma. Já o abandono escolar ocorre quando o estudante deixa a escola em definitivo (Abramovay \& Castro, 2003).

Segundo Rumberger (2006a), identificar as causas de evasão escolar é extremamente difícil, pois este fenômeno é influenciado por vários fatores, sejam eles relacionados aos estudantes ou às suas famílias, escolas e comunidades. Este autor entende a evasão escolar como um processo, e não apenas como um momento pontual na vida do estudante, considerando este fenômeno como o estágio final de um dinâmico e cumulativo processo de desengajamento da escola.

Outros fatores também estão associados à evasão escolar. No estudo de Silva (2005) realizado em uma escola do Pará, foram investigados os fatores associados à evasão escolar sob a perspectiva de vários agentes escolares. Na visão do diretor da escola, tal processo se justifica devido a uma falta de política de incentivo aos estudos que articule as necessidades profissionais dos alunos com as estudantis. Os docentes relacionaram este fenômeno às condições econômicas das famílias e dos estudantes, relatando que muitas destas são obrigadas a sair do município em busca de empregos. A migração implica, muitas vezes, o trabalho dos jovens estudantes do Ensino Médio, que acabam por ficar desestimulados a estudar e sem muitas perspectivas futuras. Do ponto de vista do coordenador pedagógico, este processo está ligado ao baixo rendimento dos alunos: ao se depararem com uma nota baixa, entram em desespero e não se sentem capazes de ser aprovados, desmotivando-se e evadindo da escola.

Ainda em relação ao processo de evasão escolar, Rumberger (2006a) apresenta duas perspectivas para explicar o fenômeno, uma em relação à visão do aluno e outra relacionada a uma perspectiva institucional. Em relação à perspectiva individual do aluno, este autor discute como os valores, atitudes e comportamentos dos estudantes podem contribuir para a saída destes da escola. Especificamente, como a falta de engajamento acadêmico ou no processo de aprendizagem, assim como o desengajamento social ou nas dimensões da escola, podem influenciar a decisão de se retirar da mesma.

No que se refere à dimensão institucional, não apenas a escola como, também, outras instituições - como a família e a comunidade -, podem influenciar tanto na permanência quanto na saída dos alunos da escola. Especificamente no contexto escolar, os recursos que esta instituição oferece ou deixa de oferecer podem tanto influenciar na efetivação do engajamento e desempenho acadêmico, quanto contribuir para o processo de desengajamento e evasão do estudante (Rumberger, 2006a).

Nesta mesma direção, Abramovay e Castro (2003) discutem as influências da infraestrutura no processo de ensino e aprendizagem no Ensino Médio. As autoras alegam que investigar tais influências é uma tarefa de difícil mensuração, mas afirmam que uma escola organizada, equipada e limpa cria um ambiente favorável ao trabalho de todos, atuando na motivação dos professores e funcionários e auxiliando os alunos a desenvolverem seu potencial (por meio dos recursos que lhes são oferecidos).

Em relação às estratégias para prevenção da evasão escolar, sabendo que o processo envolvendo a mesma não se resume ao momento em que o aluno deixa a escola, Rumberger (2006b) apresenta que as estratégias de prevenção devem começar cedo junto aos alunos, pois as atitudes e comportamentos problemáticos que podem levá-los à evasão também começam geralmente cedo. 
Outro apontamento de Rumberger (2006b) para esta prevenção refere-se ao fato de que um programa de intervenção para a prevenção da evasão escolar deve ir além da dimensão do aluno, estendendo-se para o contexto ambiental, fornecendo-se recursos e suporte para famílias, escolas e comunidades. No estudo de Silva (2005), o diretor da escola analisada também defende a ideia de que um programa de prevenção da evasão é um trabalho realizado junto à comunidade.

Tendo em vista os fundamentos descritos, a pesquisa desenvolvida teve como objetivo refletir sobre os processos de inclusão e evasão escolar, discutindo como a motivação pode estar associada a estes processos.

\section{Método}

De acordo com os pressupostos de Andrade (2003), este estudo se caracteriza de duas formas. Quanto aos seus objetivos, pode ser considerado um estudo exploratório e, quanto ao seu objeto, caracteriza-se como uma pesquisa de natureza bibliográfica.

\section{Discussão}

Partindo do postulado de que a motivação possui um papel significativo na vida do aluno por estar atrelada tanto a um maior engajamento nas tarefas que permeiam o contexto escolar quanto à formação integral de um cidadão crítico e realizado (Bzuneck, 2009), sugere-se, neste artigo, pensar na importância da motivação do aluno no contexto acadêmico, que parece ser um aspecto preocupante no Ensino Médio, uma vez que algumas pesquisas (Abramovay \& Castro, 2003; Machado, 2005) evidenciam que um dos principais problemas neste nível de ensino diz respeito à motivação, ou melhor, à falta dela.

Esta variável também está vinculada aos processos de inclusão (ou exclusão) e evasão escolar dos estudantes. No que se refere à inclusão do aluno no contexto educacional, este processo pode apresentar um efeito contrário quando segrega o aluno de seu contexto regular de sala de aula para aulas que, até então, teriam por objetivo dar um suporte diferenciado que outrora este aluno não pudera receber. Salvo casos em que o encaminhamento para classes especiais é muito bem estruturado e supervisionado, quando não realizado desta forma o processo de inclusão pode exercer um efeito direto na motivação do aluno.

Assim, tanto quando os níveis quanto a qualidade da motivação estão prejudicados, tal fato corrobora para que cada vez mais o estudante não se empenhe nas atividades acadêmicas e, assim, contribua para o processo de desengajamento, que pode terminar com a evasão do ambiente escolar. Conforme Rumberger (2006b), alguns fatores relacionados a esse processo de evasão escolar podem estar associados aos valores, atitudes e comportamentos dos próprios alunos, e outros às questões institucionais, como, por exemplo, a falta de recursos escolares e falta de apoio familiar. 0 fato é que, sejam quais forem os fatores que estão relacionados à evasão escolar, grande parte deles pode ter impacto na motivação do estudante.

A partir destas considerações é possível afirmar que a motivação pode exercer uma dupla função, ora como causa ora como consequência dos processos de inclusão e evasão escolar. Quando os procedimentos pedagógicos e o trabalho planejado e bem estruturado fazem parte do processo de inclusão do aluno no ambiente estudantil, os desdobramentos tenderão a repercutir para a obtenção de um estudante mais motivado e, assim, mais engajado no meio acadêmico. Por outro lado, dentre os diversos fatores que estão associados à evasão escolar, muitos deles provêm da motivação do aluno, fazendo com que esta variável anteceda, ou mesmo, possa ser a causa do desengajamento do estudante do universo escolar.

\section{Considerações Finais}

O Ensino Médio possui características singulares no processo de escolarização do estudante no Brasil. Pelo fato de ser a última etapa da Educação Básica e a que antecede o acesso ao Ensino Superior, é possível dizer que o Ensino Médio apresenta uma característica transicional: da escola para a faculdade, da escola para o trabalho, ou mesmo da escola para a família. Diversas são as adversidades com as quais os estudantes deste nível de ensino se deparam, fazendo com que, muitas vezes, estas repercutam na motivação dos mesmos.

Sabendo da amplitude que a variável motivação pode atingir quanto ao fomento de níveis de discussão 
na educação em geral, este estudo se restringiu a um pequeno recorte focado nos processos de inclusão e evasão no contexto escolar. Assim, procurou-se refletir o quanto os procedimentos de inclusão do aluno precisam ser bem planejados e estruturados para que estes influenciem positivamente na motivação do estudante. Sob outra ótica, procurou-se também discutir o processo de evasão do aluno, estabelecendo relações entre os fatores desencadeantes de tal processo, dentre eles, o fator motivacional.

Mesmo diante das limitações compreendidas neste trabalho, torna-se necessário ressaltar o importante papel que a motivação adquire no contexto escolar, enaltecendo a necessidade de que, cada vez mais, esta discussão se faça presente nos diversos segmentos da educação pública no Brasil.

\section{Referências}

Abramovay, M., \& Castro, M. G. (2003). Ensino médio: múltiplas vozes. Brasilia: MEC.

Andrade, M. M. (2003). Introdução à metodologia ao trabalho científico (6a ed.). São Paulo: Atlas.

Bzuneck, J. A. (2009). A motivação do aluno: aspectos introdutórios. In E. Boruchovitch \& J. A. Bzuneck (Orgs.), A motivação do aluno: contribuições da psicologia contemporânea (pp.9-36). Petrópolis: Vozes.

Cavallari, J. S. (2010). O equívoco no discurso da inclusão: o funcionamento do conceito de diferença no depoimento de agentes educacionais. Revista Brasileira de Linguística Aplicada, 10(3), 667-680.

Costa, E. R., \& Boruchovitch, E. (2006). A auto-eficácia e a motivação para aprender: considerações para o desem- penho escolar dos alunos. In R. G. Azzi \& S. A. J. Polydoro (Orgs.), Auto-eficácia em diferentes contextos (pp.87-109). Campinas: Alínea.

Leonardo, N. S. T., Bray, C. T., \& Rossato, S. P. M. (2009). Inclusão escolar: um estudo acerca da implantação da proposta em escolas de ensino básico. Revista Brasileira de Educação Especial, 15(2), 289-306.

Machado, N. M. L. (2005). A escola ideal: como os adolescentes percebem e idealizam o meio escolar (Dissertação de mestrado não-publicada). Pragrama de Pós-Graduação em Educação, Universidade Estadual de Campinas.

Mittler, P. (2003). Educação inclusiva: contextos sociais. Porto Alegre: Artmed.

Plaisance, E. (2010). Ética e inclusão. Caderno de Pesquisa, 40(139), 13-43.

Rumberger, R. W. (2006a). Why students drop out of school. In G. Orfield (Ed.), Dropouts in America: Confronting the graduation rate crisis (pp.131-155). Cambridge: Harvard Education Press.

Rumberger, R. W. (2006b). What can be done to reduce the dropout rate? In G. Orfield (Ed.), Dropouts in America: Confronting the graduation rate crisis (pp.243-254). Cambridge: Harvard Education Press.

Sanches, I., \& Teodoro, A. (2006). Da integração à inclusão escolar: cruzando perspectivas e conceitos. Revista Lusófona de Educação, 8(8), 63-83.

Sant'Ana, I. M. (2005). Educação inclusiva: concepções de professores e diretores. Psicologia em Estudo, 10(2), 227-234.

Silva, F. C. S. (2005). A evasão escolar de jovens do ensino médio de uma escola pública de Itaituba, Pará (Dissertação de mestrado não-publicada). Programa de Pós-Graduação em Educação, Universidade Estadual de Campinas.

Recebido em: 28/7/2011

Versão final em: 16/9/2011

Aprovado em: 20/12/2011 
